\title{
Insucesso escolar: formação de professores de matemática em questão School failure: Mathematics teachers training in question
}

\author{
ROSALINO SUBTIL CHICOTE ${ }^{1}$ \\ GERALDO VERNIJO DEIXA ${ }^{2}$
}

\section{Resumo}

O artigo discorre sobre a contribuição da formação de professores diante do insucesso escolar na disciplina de matemática. A questão de pesquisa foi: em que medida a formação de professores de matemática interfere diante do insucesso escolar? A pesquisa buscou situar a contribuição da formação de professores de matemática diante do insucesso escolar. Foram entrevistados 26 professores da Província de Cabo Delgado, em Moçambique. O estudo obedeceu à abordagem qualitativa. Os resultados apontam que cerca de 4 em cada 5 professores afirmaram que a formação de professores contribuiu positivamente para construir bases para lidar com o insucesso escolar na disciplina de matemática. Assim, concluímos que há uma aproximação entre a formação de professores de matemática e o grau de contribuição para lidar com o insucesso escolar.

Palavras-chave: insucesso escolar, formação de professores, Educação Matemática.

\begin{abstract}
Abrstract
The article discusses the contribution of teachers training before school failure in mathematics. The research question was: to what extent does the training of mathematics teachers interfere in the face of school failure? The research sought to situate the contribution of mathematics teachers training in the face of school failure. Twenty-six teachers of mathematics from Cabo Delgado Province, Mozambique, were interviewed. The study followed a qualitative approach. The results shows that about 4 out of 5 teachers stated that teacher training contributed positively to build foundations for dealing with school failure in the math discipline. Thus, we conclude that there is an approximation between teachers training in mathematics and degree of contribution to addressing school failure.
\end{abstract}

Keywords: school failure, teacher training, mathematic education

\footnotetext{
1 Licenciado em Ensino de Matemática pela UP-Quelimane. Mestrando em Educação/Currículo na Universidade Licungo - rschicote1@gmail.com

${ }^{2}$ Doutor em Ensino de Ciências e Educação Matemática pela Universidade Estadual de Londrina, Brasil gdeixa@gmail.com
} 


\section{Introdução}

O insucesso escolar na disciplina de matemática é um dos temas que tem merecido atenção de pesquisadores ao longo dos últimos anos. A produção científica sobre a temática é diversificada. Apesar do crescente volume de pesquisas sobre a temática, o insucesso escolar na disciplina de matemática ainda prevalece no seio de muitas sociedades, logo a sociedade moçambicana não está alheia a essa realidade.

Esta situação é preocupante pois, "o insucesso escolar gera insucesso social” (CHARLOT apud ERYDICE, 1995). A mesma posição é expressa por Fonseca (1999, p. 513) quando sublinha que "o insucesso escolar é corolário de muitos problemas que têm por denominador comum a não-satisfação das necessidades reais da criança. Por exemplo, o insucesso escolar provoca a evasão dos alunos; a mendicidade; a marginalidade; aumento da taxa de analfabetismo, entre outros problemas.

Algumas pesquisas sobre insucesso escolar na disciplina de matemática buscam identificar factores, analisar o grau de culpabilidade dos intervenientes. Outras buscam explicar o insucesso do ponto de vista da sociologia da educação. Da Revisão de Literatura realizada, entendemos que ainda há poucas pesquisas publicadas que realizam a conexão entre insucesso escolar e formação de professores de matemática. Uma conexão nesse sentido, foi realizada recentemente por Viegas (2017), uma pesquisadora Cabo Verdiana, na sua tese de doutoramento.

Nesse trabalho, a autora defende que "urge analisar o papel da formação de professores de matemática no que diz respeito ao insucesso escolar desta disciplina" (Viegas (2017, p. 58). Desse modo, indagamos: em que medida a formação de professores de matemática interfere diante do insucesso escolar?

O nosso objecto de estudo foi o grau de interferência da formação diante do insucesso escolar na disciplina de matemática. A intenção foi situar a contribuição da formação de professores de matemática diante do insucesso escolar. Para tal, identificamos representações de insucesso escolar em matemática; apontamos momentos da formação de professores em que se debate em torno do insucesso escolar em matemática; reconhecemos estratégias de apoio a alunos em situação de insucesso escolar em matemática provenientes da formação. 
A formação de professores de matemática poucas vezes é tomada como objecto de estudo na análise do insucesso escolar. Esta pesquisa pode apoiar na divulgação e reflexão sobre estratégias utilizadas pelos professores de matemática aplicadas à alunos em situação de insucesso escolar. Ademais, indica-se o sentimento dos professores face a insumos da formação diante do insucesso escolar em matemática.

\section{Revisão de Literatura}

\section{Insucesso Escolar na disciplina de Matemática}

Para Almeida (2011), as tentativas de conceituar o insucesso escolar encerram dois pontos de vista: insucesso escolar como quantificação de um facto escolar observável e insucesso escolar como um fenômeno difícil de quantificar e complexo. De acordo com Eurydice (1995, p. 49),

\footnotetext{
o insucesso escolar traduz a incapacidade do sistema educativo em assegurar uma verdadeira igualdade de oportunidades, (...) a incapacidade do sistema em compatibilizar uma educação de qualidade com uma educação para todos, capaz de assegurar a cada um uma parte activa na sociedade.
}

Eurydice (1994) conceitua o insucesso escolar na perspectiva das políticas educativas. A mesma abordagem consta em Martins (1993, p. 9), ao argumentar que uma "entidade apresenta insucesso quando não consegue atingir os objectivos propostos ou isso não acontece no tempo previsto." Portanto, predomina, nesse sentido, o conceito de insucesso escolar como quantificação de um fato observável no seio escolar.

No sistema educativo moçambicano essa visão foi a mais predominante nos últimos 15 anos. A maior preocupação das escolas, sob orientação do Ministério da Educação, foi o aproveitamento pedagógico e elevadas taxas de conclusão. No entanto, pouco se presta atenção a qualidade desses concluintes. É neste contexto que Mendonça (2006, p. 551) sustenta que "qualquer política educativa consegue facilmente alterar as taxas de sucesso/insucesso, consoante os propósitos e as metas a atingir". Os problemas que decorrem da alteração de uma política educativa para outra levam poucos anos para se manifestar. Geralmente, a implementação de uma política educativa não é extensiva a outras instituições do mesmo sistema ecológico.

A visão de insucesso escolar como quantificação de um fato observável no seio escolar, no contexto moçambicano, sofreu críticas tendo em conta que muitos concluintes do 
ensino primário ( $1^{\mathrm{a}}$ a $7^{\mathrm{a}}$ classe, alunos de 6 a 13 anos de idade) e secundário $\left(8^{\mathrm{a}}\right.$ a $12^{\mathrm{a}}$ classe, alunos de 14 a 18 anos de idade) ainda mostravam dificuldades em leitura e escrita bem como em operações elementares de Matemática. Esse fato obrigou as instituições de formação de professores a rever os currículos de formação. Tal revisão aconteceu pelo reconhecimento que nem todas as realidades podem ser encaradas por meio da quantificação devido ao entrelaçamento entre fatores de diferentes índoles.

O outro ponto de vista, destaca o insucesso escolar como um fenômeno difícil de quantificar e complexo, tem seu foco "nas disfuncionalidades presentes no indivíduo, escola e sociedade e ainda na forma como estas três entidades se articulam" Martins (1993, p. 9). Por essa razão Mendonça (2006, p. 549) cita fatores em torno dos intervenientes:

\footnotetext{
é impossível atribuir a responsabilidade do insucesso escolar a uma só instância, pois é na confluência de inúmeros factores que o concebemos: as condições sociais, económicas e culturais, a família, o sistema educativo e a própria escola.
}

Coloca-se em causa a forma pela qual os três intervenientes se articulam como fator preponderante de insucesso escolar. A articulação pressupõe a identificação de teias de relações, faces e interfaces associadas aos três grupos de intervenientes. O processo exige uma profundidade na exploração das representações sobre o insucesso escolar na disciplina de matemática de cada grupo.

Deste modo, a abordagem que parece ser mais adequada para a problemática recai sobre o paradigma qualitativo de investigação por perceber que estabelece um diálogo entre os vários intervenientes do processo educativo (pais, encarregados de educação, alunos, professores, entre outros) para compreender as razões subjacentes ao insucesso.

Para Jamati apud Perreira (2010, p. 2),

a noção de insucesso é relativa, uma vez que só faz sentido numa instituição escolar e num determinado momento dessa instituição, pois diz respeito aos objectivos da escola, representados num programa e numa progressão de níveis, não podendo rotular o aluno permanentemente de um ser incapaz de atingir o sucesso.

Uma posição contraditória a expressa por Jamati é defendida por César et al. apud Almeida (2011, p.16-17), nos seguintes termos,

o insucesso escolar é um fenómeno de aparecimento precoce (manifesta-se desde os primeiros anos de escolaridade), cumulativo (quem já teve insucesso, no passado, tem mais probabilidades de o vir a ter novamente) e selectivo (pois 
não afecta de igual modo as crianças que vêm de diversos meios sócio-culturais)

A primeira citação mostra que o insucesso escolar não está vinculado ao aluno, mas sim a escola e seu sistema em geral. Por essa razão, não se deve estampar um aluno com a marca insucesso escolar na disciplina de matemática. Todavia, na segunda citação defende-se que o insucesso escolar reside permanentemente no seio dos alunos embora em diferentes níveis. Essa forma permanente de insucesso pode estar associada às atitudes que os alunos têm sobre a disciplina de matemática.

\section{Metodologia}

Abordamos o problema de pesquisa a partir do enfoque qualitativo. A escolha desta forma de abordagem justifica-se pela necessidade de explorar pontos de vista dos participantes através das suas respostas com vista a um aprofundamento da temática no contexto moçambicano, isto é, analisando as suas singularidades e experiências individuais sobre a sua formação e articulação com o insucesso escolar na prática docente (LÜDKE e ANDRÉ, 1986).

Classificamos a pesquisa em exploratória e descritiva quanto aos objetivos porque buscamos informações com a finalidade de formular problemas de pesquisa mais específicos tendo em conta que, apesar da literatura internacional apresentar causas do insucesso escolar, no âmbito nacional são raras as pesquisas que abordam esse fenômeno sob o ponto de vista qualitativo. Desse modo, o problema não ganhou maior familiaridade pelos pesquisadores alicerçados no paradigma qualitativo, havendo necessidade de buscar maior esclarecimento de modo a formular hipóteses relacionadas aos problemas (GIL, 2002).

A pesquisa envolveu 26 professores de matemática de diferentes escolas da Província de Cabo Delgado. Os professores foram escolhidos pelas direções distritais da Educação da Província de Cabo Delgado para participar da Capacitação de Professores do Ensino Secundário Geral na Disciplina de Matemática, evento organizado pela Direcção Nacional de Ensino Secundário Geral.

Todos os participantes, 26 professores, foram do gênero masculino. Isso significa que não houve participantes do gênero feminino, por trás disso pode estar o critério de seleção utilizado. Por outro lado, esse fato indica que, em Moçambique, há poucas professoras 
licenciadas formadas na área de Ensino de Matemática. Julgamos que deve constituir uma preocupação pois, desse modo, parece que os cursos de Licenciatura em Ensino de Matemática são concebidos especificamente para o gênero masculino.

Dos 26 participantes, 18 possuíam mais de 31 anos de idade, 6 possuíam idades compreendidas entre 26 e 30 anos. Os anos de experiência em ensino de matemática variam entre 2 a 34 anos.

Dos participantes da pesquisa, 24 foram formados em Instituições de Ensino Superior (Instituto Superior de Ciências e Tecnologia Alberto Chipande- ISCTAC, Universidade Católica de Moçambique-UCM, Universidade Eduardo Mondlane - UEM e Universidade Pedagógica-UP). Todas essas instituições funcionam em Moçambique.

Ainda na constituição dos participantes, identificamos 2 professores formados por Instituições de Formação de Professores do Ensino Básico (Ajuda de Desenvolvimento de Povo para Povo- ADPP e Instituto de Formação de Professores-IFP), portanto são professores formados para actuarem no Ensino Básico ( $1^{\mathrm{a}}$ a $7^{\mathrm{a}}$ classe, alunos com idades compreendidas entre 6 e 13 anos). Por diversas razões que não interessa mencionar, os professores lecionam a disciplina de matemática no Ensino Secundário Geral (ESG).

Esses professores foram preparados para atuar no Ensino Básico, portanto, aprenderam como ensinar disciplinas do Ensino Básico. Ao actuar no Ensino Secundário Geral, lidam com alunos de 14 a 18 anos de idade. Assim sendo, questionamos: como é que lidam com insucesso escolar?

Esse fato conduziu-nos as seguintes indagações:

(i) Que matemática é ensinada por professores formados para atuarem no Ensino Básico, porém atuam no Ensino Secundário Geral?

(ii) Qual o grau de compreensão de conteúdos de matemática que seus alunos apresentam?

(iii) Que conhecimentos os professores de matemática formados para atuar no Ensino Básico, mas atuam no Ensino Secundário Geral, mobilizam para desenvolver o ensino de matemática?

(iv) Como é que a formação que tiveram se conecta a sua prática profissional? 
(v) Como se configura o conhecimento do conteúdo de um professor formado para atuar no Ensino Básico, que atua no Ensino Secundário Geral?

(vi) Como se configura o conhecimento didático do conteúdo de um professor formado para actuar no Ensino Básico, mas atua no Ensino Secundário Geral?

(vii) O que podemos aprender da prática profissional de um professor formado para atuar no Ensino Básico, mas que atua no Ensino Secundário Geral?

Estas são algumas indagações que achamos que merecem alguma atenção de pesquisadores da Educação Matemática. Uma resposta a cada um dos problemas levantados seria de relevante contribuição para a nossa área.

A seguir apresentamos a tabela que espelha a distribuição de professores por nível académico e instituição formadora. Na tabela 1, SR significa sem referência, isto é, o professor não fez referência a instituição que o formou.

Tabela 1. Distribuição de níveis académicos dos professores por instituição formadora

\begin{tabular}{l|c|c|c|c|c|c|c|c|}
\hline \multirow{2}{*}{ Nível Académico } & \multicolumn{7}{|c|}{ Instituição formadora } & \multirow{2}{*}{ Total } \\
\cline { 2 - 9 } & ADPP & IFP & ISCTAC & UCM & UEM & UP & SR & \\
\hline Médio (10 $+\mathbf{2})$ & 1 & 1 & 0 & 0 & 0 & 0 & 0 & 2 \\
\hline Médio (12a +1) & 0 & 0 & 0 & 0 & 0 & 5 & 0 & 5 \\
\hline Bacharelato & 0 & 0 & 0 & 0 & 1 & 0 & 0 & 1 \\
\hline Licenciatura & 0 & 0 & 1 & 8 & 0 & 8 & 1 & 18 \\
\hline Total & 1 & 1 & 1 & 8 & 1 & 13 & 1 & 26 \\
\hline Fr & 3,8 & 3,8 & 3,8 & 30,7 & 3,8 & 50 & 3,8 & \\
\hline
\end{tabular}

Fonte: dados da pesquisa, 2019.

A tabela acima evidencia que 18 dos 26 (69\%) professores possuem o nível de licenciatura. Atualmente, o curso de Licenciatura em Ensino de Matemática (LEM) tem a duração de 4 anos e a condição de candidatura é possuir $12^{\mathrm{a}}$ classe ou equivalente. Da tabela 1 , verifica-se que 5 dos $26(19 \%)$ professores tiveram a formação no modelo $12^{\text {a }}$ +1 , ou seja, depois da $12^{\mathrm{a}}$ classe (17 a 18 anos de idade), o formando ingressa numa formação com a duração de 1 ano. Essa modalidade de formação foi introduzida na UP em colaboração como o Ministério da Educação como forma de atender as necessidades 
de professores para o Ensino Secundário Geral ( $8^{\mathrm{a}}$ a $12^{\mathrm{a}}$ classe, alunos com idades compreendidas entre 14 a 18 anos) visto que as licenciaturas duram 4 anos e o Ministério da Educação pretendia resolver um problema pontual. Ainda na mesma tabela, nota-se que 2 dos 26 professores tiveram formação no modelo de $10^{\mathrm{a}}+2$ anos. Ambos modelos conferem a formação de professores de nível médio.

Para a recolha de dados, foi construído um roteiro de entrevista e, posteriormente, prétestado para garantir a sua validade e fiabilidade. Esse Insucesso escolar: formação de professores de matemática em questão

$\mathrm{O}$ instrumento foi composto por perguntas abertas e fechadas. Utilizamos perguntas abertas para permitir o esclarecimento da opção escolhida pelo professor. A recolha de dados foi realizada no ginásio do Instituto de Formação de professores Alberto Chipande, em Pemba, na Província de Cabo Delgado, em junho de 2019. Antes da aplicação do instrumento, foram explicados os objetivos da pesquisa e a pertinência de responder a todas as questões. Participaram todos os professores presentes no seminário.

Para garantir o anonimato, efetuámos a codificação do material de pesquisa por $\mathrm{P}_{1}, \mathrm{P}_{2}$, $\mathrm{P}_{3}, \ldots . \mathrm{P}_{26}$. Para as perguntas fechadas, foram determinadas as frequências absolutas e relativas. Para este tipo de questões, utilizamos na apresentação dos resultados gráficos circulares. Escolhemos este tipo de gráfico, porque se trata de variáveis qualitativas em que cada entrevistado teve a oportunidade de escolher apenas uma opção diante de outras.

As questões abertas foram analisadas em função da abordagem sugerida por Creswell (2012, p. 243):

- dividir o texto em segmentos de informação;

- rotular os segmentos por códigos (exaustão);

- produzir lista de códigos e reduzir códigos redundantes.

Depois desse processo, procuramos relacionar os códigos para formar subcategorias e as categorias correspondentes. O outro aspecto, que cabe ressaltar, é o fato da busca da relação entre os códigos emergentes e nível académico, instituição formadora e anos de experiência. Todas as questões abertas foram analisadas segundo os procedimentos expostos anteriormente. Apresentamos em quadros e uma transcrição que demonstra a linha de pensamento da subcategoria. 


\section{Apresentação e análise dos resultados}

Nesta seção, apresentamos resultados da pesquisa obedecendo a sequência estabelecida no instrumento de recolha de dados. Criamos alguns subtítulos para apresentação de resultados das perguntas. A seguir apresentamos os resultados.

\section{Insucesso escolar em matemática}

A primeira pergunta colocada, referente ao insucesso escolar, buscou identificar representações sobre insucesso escolar que os 26 entrevistados possuem. Dessa pergunta, o conceito de insucesso escolar na disciplina de matemática gerou uma categoria: aproveitamento pedagógico. Em seguida, apresentamos as subcategorias, unidades de significados da categoria.

Quadro 1. Categorias do Insucesso Escolar em matemática

\begin{tabular}{|c|l|l|}
\hline \multicolumn{1}{|c|}{ Categoria } & Subcategoria & Unidades de significado \\
\hline \multirow{3}{*}{ Aproveitamento Pedagógico } & Quantitativo & Resultado negativo \\
\cline { 2 - 3 } & \multirow{2}{*}{ Qualitativo } & Baixa compreensão \\
\cline { 3 - 3 } & & Alcance de objetivos \\
\hline
\end{tabular}

Fonte: dados da pesquisa, 2019.

O aproveitamento pedagógico, tradicionalmente, está associado a ideia de notas ou resultado escolar (global). Porém, os entrevistados produziram respostas cujos códigos indicam a separação desta categoria em duas vertentes: quantitativa e qualitativa.

A quantitativa diz respeito às notas, resultado cumulativo em si. A qualitativa traduz a visão intrínseca ao processo. Indícios dessa separação já aparecem expostos em Almeida (2011) quando sublinha que o insucesso escolar em matemática é visto como um fenômeno quantificável e, por outros, como um fenômeno difícil de mensurar.

Quadro 2. Representações sobre insucesso escolar em matemática da subcategoria quantitativa 


\begin{tabular}{|c|c|l|}
\hline $\begin{array}{c}\text { Unidades de } \\
\text { significado }\end{array}$ & Exemplo de unidade de contexto & Unidade de registo \\
\hline $\begin{array}{c}\text { Resultado } \\
\text { negativo }\end{array}$ & $\begin{array}{c}\text { "Quando no final do PEA temos, tenho } \\
\left.\text { resultados não satisfatórios" ( } \mathrm{P}_{14}\right) .\end{array}$ & $\mathrm{P}_{1}, \mathrm{P}_{2}, \mathrm{P}_{6}, \mathrm{P}_{12}, \mathrm{P}_{13} \mathrm{P}_{14}, \mathrm{P}_{17}$, \\
$\mathrm{P}_{18}, \mathrm{P}_{19}, \mathrm{P}_{21}, \mathrm{P}_{22}, \mathrm{P}_{23}, \mathrm{P}_{24}, \mathrm{P}_{26}$ \\
\hline
\end{tabular}

Fonte: dados da pesquisa, 2019.

O quadro 2 ilustra que 14 dos $26(53,8 \%)$ entrevistados concebem o insucesso escolar como o resultado negativo que um aluno pode obter. Isso quer dizer que mais da metade dos entrevistados conceituam o insucesso escolar pelo critério pedagógico (resultados escolares). Para Mendonça (2006) esta forma de conceber o fenômeno, em Portugal, deriva da inexistência de uma unanimidade semântica na definição do conceito. Porém, no contexto moçambicano, ela está enraizada nas políticas educativas predominantes de um tempo a esta parte. Isso significa que embora tenha havido transformação curricular, tal perspectiva ainda prevalece.

Com base nos resultados do quadro 2, podemos afirmar que a formação de nível superior desses professores não mudou sua concepção sobre insucesso escolar em matemática.

Das respostas dos entrevistados, o insucesso escolar se refere ao insucesso do indivíduo (aluno). Esse resultado converge com o da tese de Viegas (2017) quando constata que os professores de matemática com formação de nível superior atribuem muita culpa aos alunos pelo insucesso escolar na disciplina.

Quadro 3. Representações sobre insucesso escolar em matemática da subcategoria qualitativa

\begin{tabular}{|c|c|c|}
\hline $\begin{array}{c}\text { Unidades de } \\
\text { significado }\end{array}$ & \multicolumn{1}{|c|}{ Unidade de contexto } & Unidade de registo \\
\hline Baixa & $\begin{array}{l}\text { "Insucesso escolar na disciplina de matemática } \\
\text { é os alunos não conseguirem perceber }(. . .) \text { os } \\
\text { conteúdos leccionados pelos professores, não } \\
\text { compreensão } \\
\text { professores" }\end{array}$ & $\mathrm{P}_{5}, \mathrm{P}_{7}, \mathrm{P}_{8}, \mathrm{P}_{15}, \mathrm{P}_{16}, \mathrm{P}_{20}, \mathrm{P}_{25}$ \\
\hline
\end{tabular}

Fonte: dados da pesquisa, 2019. 
Dos 26 entrevistados, 7 (26,9\%) produziram respostas que se enquadram na subcategoria qualitativa. Quase metade dos entrevistados possuem a formação do regime $12^{\mathrm{a}}+1$ ano. Outros dois entrevistados possuem o nível de Licenciatura em Ensino de Matemática. Há diversidade de nível acadêmico dos entrevistados cujas respostas se enquadram nessa subcategoria. A incapacidade de resolver exercícios é vista como um indicador do insucesso escolar na disciplina de matemática.

Muitos fatores contribuem para que um aluno não compreenda o conteúdo ensinado, consequentemente não consiga resolver exercícios. Viveiro (2012) faz referência às práticas do professor. A autora explica que "são práticas que se prendem com a dificuldade em apoiar as turmas numerosas, com o ritmo das aulas inadequado às turmas e com a falta de tempo para estar com alunos que têm dificuldades" (p. 350).

No contexto moçambicano, turma numerosa se apresenta como realidade para muitas escolas. Esse elemento dificulta o acompanhamento individualizado dos alunos (CHAMUAITA e DEIXA, 2016). Verifica-se que, depois do professor propor exercícios aos alunos, pelo número de alunos por turma, torna-se difícil efectuar um acompanhamento e verificar as resoluções de todos.

Quadro 4. Representações sobre insucesso escolar em matemática da subcategoria qualitativa

\begin{tabular}{|c|c|c|}
\hline $\begin{array}{l}\text { Unidades de } \\
\text { significado }\end{array}$ & Unidade de contexto & $\begin{array}{l}\text { Unidade de } \\
\text { registo }\end{array}$ \\
\hline $\begin{array}{c}\text { Alcance de } \\
\text { objetivos }\end{array}$ & $\begin{array}{l}\text { "Na minha opinião, insucesso escolar na disciplina de } \\
\text { matemática é o fracasso que os alunos e os professores têm } \\
\text { por não atingir objectivos traçados duma(s) aula }(s) "\left(P_{10}\right) \text {. } \\
\text { Quando o aluno não está em condições de transitar de uma } \\
\text { unidade ou tema para outro }\left(P_{9}\right) \text {. É o não alcance dos } \\
\text { objectivos instrutivos e educacionais bem como as } \\
\text { competências básicas esperadas no aluno }\left(P_{3}\right)\end{array}$ & $\mathrm{P}_{3}, \mathrm{P}_{9}, \mathrm{P}_{10}, \mathrm{P}_{11}$ \\
\hline
\end{tabular}

Fonte: dados da pesquisa, 2019.

A segunda vertente da subcategoria qualitativa diz respeito ao insucesso escolar como incapacidade de alcançar objetivos. Os entrevistados cujas respostas recaem nesta categoria são licenciados em ensino de matemática. A tese de que o sucesso escolar pode 
ser identificado a partir do alcance dos objetivos está alicerçada na Teoria Behavorista. Verificamos que o conceito de insucesso escolar apresentado pelos quatro entrevistados emerge da orientação curricular em vigor no Ensino Secundário Geral.

\section{Estratégias para apoiar alunos em situação de insucesso escolar}

Os 26 professores revelaram que nas suas aulas de matemática têm prestado atenção especial aos alunos em situação de insucesso escolar. De modo geral, as estratégias dos inqueridos podem ser sintetizadas da seguinte forma:

- Apoio aos alunos na resolução de um exercício na sala de aulas;

- Repetição de uma aula caso constate que os alunos não a compreenderam;

- Indução para os alunos intervirem no decurso da aula;

- Orientação para criação de grupos de estudo heterogêneos;

- Elaboração de planos individualizados de aprendizado direcionado aos alunos.

As estratégias sugeridas pelos entrevistados são diversificadas com ênfase no trabalho dentro da sala de aulas. O reconhecimento de que os planos de aula podem ser elaborados tendo em conta a heterogeneidade da turma é pouco saliente.

Algumas estratégias são rotineiras e outras constituem uma inovação, por exemplo, a elaboração de planos direcionados para os alunos em situação de insucesso escolar. Todavia, "com um bom ou com um mau professor, o aluno fraco não consegue sucesso escolar em Matemática" (VIVEIROS, 2012, p. 342). Apesar da citação anterior demonstrar que o insucesso escolar acompanha o aluno ao longo do seu percurso escolar, acreditamos que um esforço coletivo pode produzir alterações positivas no quadro da situação.

\section{Abordagem de Insucesso escolar em matemática na formação}

Nesta seção, em primeiro lugar, questionamos aos 26 entrevistados se alguma vez ao longo da formação se falou acerca do insucesso escolar na disciplina de matemática. $\mathrm{O}$ gráfico abaixo evidencia as respostas. 
Gráfico 1. Incidência da abordagem do insucesso escolar em matemática na formação

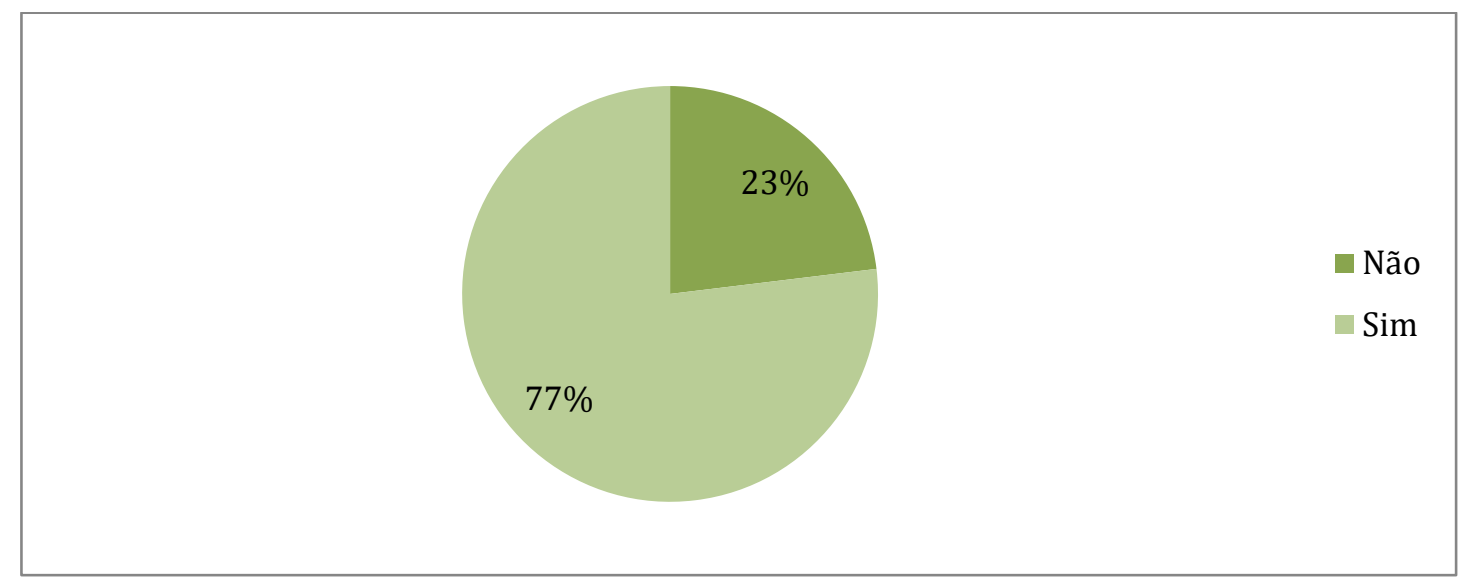

Fonte: dados da pesquisa, 2019.

O gráfico mostra que 6 (23\%) entrevistados não abordaram o tema sobre o insucesso escolar durante a sua formação. Os restantes 20 entrevistados responderam que favoravelmente (sim), questionados sobre o momento em que se abordou o insucesso escolar em matemática, $12(60 \%)$ entrevistados responderam, mas não indicaram o momento exato. Os restantes $8(40 \%)$ afirmaram que:

- Nas aulas de Didática de Matemática $\left(\mathrm{P}_{3}, \mathrm{P}_{9}, \mathrm{P}_{12}, \mathrm{P}_{21}, \mathrm{P}_{25}\right)$;

- No módulo de Psicopedagogia e Estratégias de Comunicação na sala de aulas $\left(\mathrm{P}_{26}\right)$;

- Nos debates de temas recomendados pelos professores $\left(\mathrm{P}_{4}, \mathrm{P}_{10}\right)$

Percebemos, assim, que existe a tendência das instituições formadoras de professores criarem espaços e disciplinas que abordem sobre o insucesso escolar em matemática. A pesquisa de Viegas (2017) realça que os currículos das didáticas de matemática preparam professores para a docência. Este fato, se torna evidente quando professores formados com nível de licenciatura apontam terem discutido a respeito de insucesso escolar na disciplina de didática da matemática.

\section{Contribuição da formação diante do insucesso escolar em matemática}

O gráfico abaixo destaca o grau de incidência da contribuição da formação de professores de matemática face ao insucesso escolar. Importa salientar que nenhum dos entrevistados se situou na posição neutra face ao grau de contribuição. 
Gráfico 2. Incidência na contribuição da formação para encarar o insucesso escolar em matemática

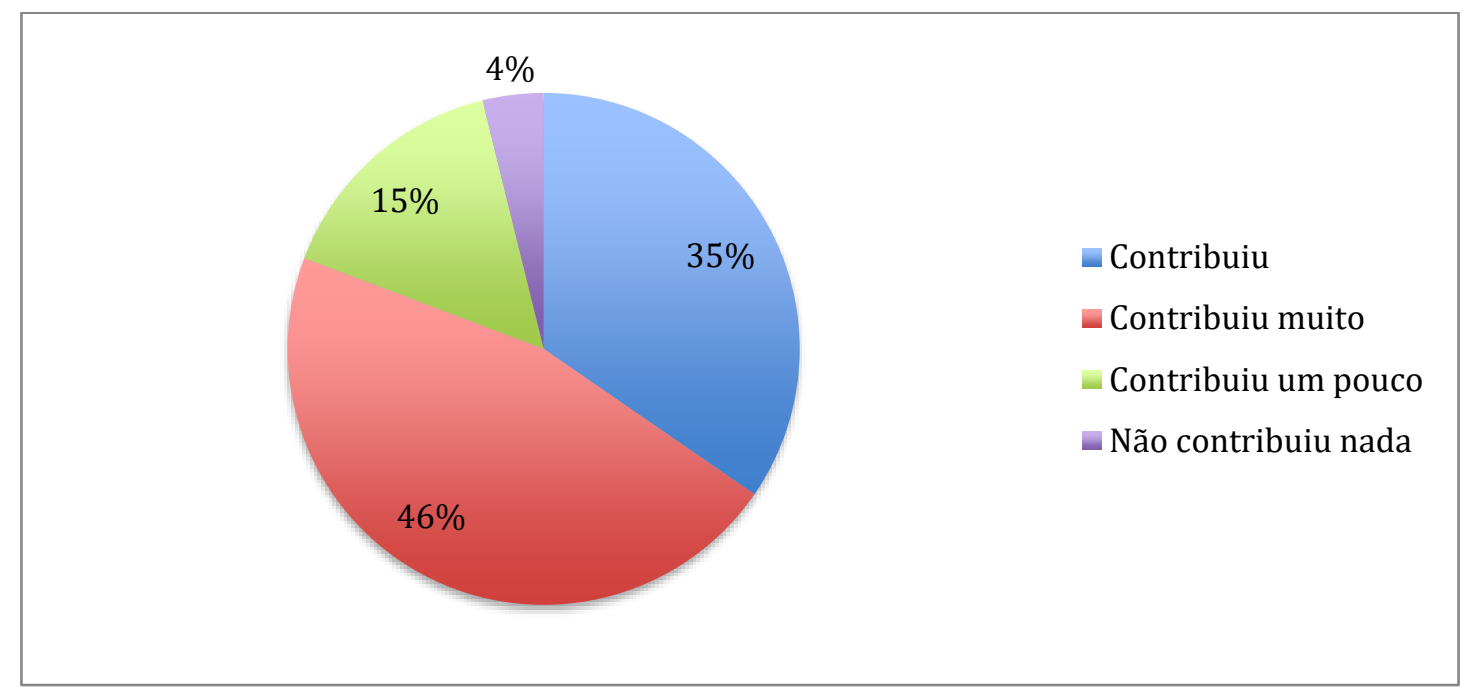

Fonte: dados da pesquisa, 2019.

Dos 26 entrevistados, 12 afirmaram que a formação gerou, em grande medida, bases para lidar com insucesso escolar na disciplina de matemática. Desse grupo, 9 entrevistados possuem o nível de licenciatura e os restantes 3 têm o nível de Bacharel, $12^{\mathrm{a}}+1$ e médio. Estes dados mostram que pouco menos da metade dos entrevistados assumiu que lida com insucesso escolar alicerçados nos conhecimentos adquiridos na formação. Nesta linha de ação, os resultados mostram que "o problema de insucesso escolar pode ser combatido através da formação de professores" (VIVEIROS, 2012, p. 353).

Outros 9 dos 26 entrevistados afirmaram que a formação contribui. Esse grupo de professores portadores dessa opinião foi constituído por licenciados e médios. Apenas 1 dos 26 dos entrevistados referiu que a formação não contribuiu em nada. Os restantes 4 referiram que a formação contribuiu um pouco. Nesses dois grupos, os níveis acadêmicos são os seguintes: Licenciado e médio $\left(12^{\mathrm{a}}+1\right)$.

Traçando um segmento de reta divisório no sentido de realizar uma transformação do grau de contribuição, entendemos que:

i. Contribuiu muito, contribui é uma resposta afirmativa, em outras palavras, um $\operatorname{sim}$.

ii. Contribuiu um pouco, não contribuiu em nada é uma resposta negativa, em outras palavras, um não.

O esquema abaixo ilustra o discurso apresentado acima. Segmento de Reta 
Divisório (SRD). As setas indicam sentidos opostos em relação a formação. A sua magnitude explica o grau de aproximação em relação a formação em matemática.

Esquema 1. Segmento de reta divisório dos graus de contribuição da formação no insucesso escolar em matemática

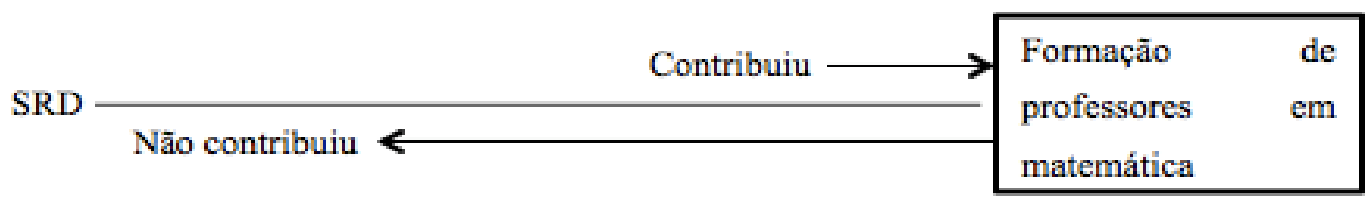

Fonte: elaboração própria dos autores.

De acordo com o esquema acima, agregando os dados, entendemos que $21(80,7 \%)$ entrevistados afirmaram que a formação contribuiu na proposição de capacidades, estratégias e metodologias para encarar a realidade do insucesso escolar na disciplina de matemática.

Por outro lado, $5(19,2 \%)$ entrevistados partilham uma opinião contrária, ou seja, defendem que a formação não contribuiu na promoção de atitudes conducentes a encarar o insucesso escolar em matemática.

A divergência de opiniões a respeito do papel da formação nesse domínio é evidente. Viegas (2017) aponta duas variáveis que a influenciam a formação de professores de matemática sobre o insucesso escolar:

i. Perfil de entrada dos candidatos à formação de professores de matemática;

ii. Plano curricular do curso de formação de professores de matemática;

Da pesquisa da autora, decorre que o perfil de entrada parece ser possível de superar através da criação de políticas que tenham como horizonte a qualidade do professor. Alternativamente, acrescentar a duração do curso, para dedicar alguma parte significativa da carga horária global num tratamento profundo do conteúdo específicos parece resultar. É nesta ordem de ideia que Buescu apud Viveiros (2012, p. 353) atesta:

\footnotetext{
se formarmos melhor os candidatos a professores de Matemática; se promovermos mecanismos de acesso à carreira docente dos melhores candidatos, tendo portanto os melhores professores a ensinar nas escolas; se ensinarmos os melhores programas; se os alunos estudarem pelos melhores manuais; e se conseguirmos fazer com que os alunos estudem mais" (...) a grande maioria dos problemas acabarão por desaparecer.
} 
Da citação acima, revela-se que a segunda variável (plano de estudo) também joga seu papel no processo de formação de professores de matemática. Na perspectiva da autora, é possível minimizar a maioria dos grandes problemas que permanecem nos sistemas educativos de diversos países. Os problemas resultam da confluência de muitas variáveis, algumas das quais estão fora da esfera do sistema educativo em si.

Assim, ressaltamos a necessidade de um trabalho colaborativo e cooperativo entre professores com vista a busca de solução para minorar a problemática do insucesso escolar em Matemática. Entendemos que uma discussão coletiva pode servir de mote na procura de alternativas para evitar abandonos, mendicidade, delinquências e outros problemas decorrentes do insucesso escolar.

\section{Conclusões e sugestões}

A realização da pesquisa foi orientada pela seguinte questão: em que medida a formação de professores de matemática interfere diante do insucesso escolar? A finalidade da pesquisa foi situar a contribuição da formação de professores de matemática diante do insucesso escolar. Para o efeito, foram entrevistados 26 professores de matemática da Província de Cabo Delgado. Esses professores possuíam níveis acadêmicos diversificados: médio, Bacharelato e Licenciatura, portanto uma heterogeneidade nas formações.

Verificamos que os professores de matemática, sujeitos da pesquisa, possuem uma representação pouco abrangente a respeito do insucesso escolar em matemática. Suas visões se circunscrevem a dimensão da incapacidade de um aluno atingir notas positivas, compreender a matéria e alcançar objectivos. Ela não sai da esfera da sala de aulas. No nosso entender, professores de matemática deveriam ter uma visão mais holística, que concebe o insucesso escolar como resultado da confluência e desarticulação de diversos factores como asseveram (Mendoça, 2006; Martins, 1993).

As últimas duas subcategorias emergentes na pesquisa estão relacionadas a face oculta do insucesso escolar em matemática. Essa face se camufla quando políticas educativas sustentam altas taxas de conclusão. De modo geral, os resultados da pesquisa indicam que as representações de insucesso escolar na disciplina de matemática divergem em sentidos dentro da mesma direcção. 
Há uma preocupação individual dos professores no sentido de provocar aprendizagem nos alunos em situação de insucesso escolar. As estratégias de apoio a alunos em situação de insucesso escolar são maioritariamente desenvolvidas dentro da sala de aulas. Emergiu uma estratégia de aplicação externa à sala de aulas, trata-se do plano individualizado de ensino e de aprendizagem. Sugerimos que o tempo para sua implementação deve ser orientado pela direcção da escola. Ademais, a mesma instância também deve realizar monitoria do processo.

Mais da metade dos professores tiveram oportunidades de discussão sobre o insucesso escolar em matemática ao longo da formação. A didática da matemática é apontada como principal espaço para tais discussões, porém na grade curricular desses cursos não há um tópico objectivo sobre insucesso escolar. Na formação de professores de nível médio também há disciplinas de componente curricular que criam espaço para discorrer sobre o assunto.

Neste segmento, sugerimos que a inclusão, de uma disciplina na grade curricular que aprofunde a questão do insucesso escolar seja objectiva, evidente e clara. Em outras palavras, propomos a inclusão de uma disciplina na estrutura curricular da formação de professores que verse sobre a problemática do insucesso escolar.

Os professores mostraram uma divergência de opinião sobre a posição da formação de professores de matemática quanto a contribuição para lidar com o insucesso escolar em matemática. No entanto, cerca de 4 em cada 5 professores afirmaram que a formação de professores contribuiu positivamente para construir bases para lidar com insucesso escolar na disciplina de matemática. Com base nos resultados concluímos que há uma aproximação entre a formação de professores em matemática e o grau de contribuição para lidar com o insucesso escolar.

Sugerimos que pesquisas futuras testem as seguintes hipóteses: (i) o grau de contribuição da formação de professores diante do insucesso escolar depende da progressão do nível acadêmico; cogitando a existência de uma disciplina que verse sobre insucesso escolar: O que precisa ser incorporado na formação de professores de matemática para minorar o insucesso escolar? 


\section{Referências}

ALMEIDA, M. M. R. Insucesso na matemática: As Percepções dos Alunos e As Percepções dos Professores. Dissertação apresentada na Universidade Portucalense Infante D. Henrique para obtenção do grau de Mestre em Supervisão e Coordenação da Educação. Universidade Portucalense. Portugal, 2011. Acesso ao 17 de julho de 2018. Disponível em http://repositorio.uportu.pt/bitstream/11328/176/2/TME\%20441.pdf

CHAMUITA, J; DEIXA, G.V. Percepções de professores de Matemática sobre estratégias da avaliação em turmas numerosas. Revista de Estudos da Educação Vol.01, no 26. Moçambique, 2016

CRESWELL, J. W. Educational research: planning, conducting, and evaluating quantitative and qualitative research. 4th ed, Pearson. 2012.

EURYDICE. A Luta Contra o Insucesso Escolar: Um Desafio Para a Construção Europeia (Araújo, Simone, Trad.). Lisboa: Departamento de Programação e Gestão Financeira do Ministério da Educação e do Programa Educação para Todos. 1995.

FONSECA, V. Insucesso escolar - Abordagem psicopedagógica das dificuldades de aprendizagem. Lisboa: Âncora Editora. 1999.

Gil, António C. Como elaborar projetas de pesquisa.- 4. ed. - São Paulo: Atlas, 2002.

LÜDKE, Menga e ANDRÉ, Marli E. D. A. Pesquisa em educação: abordagens qualitativas. São Paulo: EPU, 1986.

MARTINS, A. Insucesso Escolar e Apoio Educativo. In Martins, António \& Cabrita, Isabel. A Problemática do Insucesso Escolar. (pp. 9-25) Aveiro: Universidade de Aveiro. 1993.

MENDONÇA, A. M. F. A problemática do insucesso escolar: a escolaridade obrigatória no Arquipélago da Madeira em finais do do grau de doutor em sociologia da educação apresentada à Universidade da Madeira. Universidade da Madeira. Portugal, 2006. Acesso aos 13 de Janeiro de 2019. Disponível em https://www3.uma.pt/alicemendonca/conteudo/publica/Tese.pdf

PEREIRA, E. M. C. Insucesso escolar a matemática: Realidade ou mito? Dissertação 
para obtenção do Grau de Mestre em Supervisão Pedagógica. Universidade da Beira Interior. Portugal, 2010. Acesso aos 15 de Fevereiro de 2019. Disponível em https://ubibliorum.ubi.pt/bitstream/10400.6/2541/1/Tese.pdf

VEIGA, L. E. M. Formación de profesores de matemáticas y el fracaso escolar en la disciplina de matemáticas. Tesis doctoral presentada ao innovación en formación de profesorado, asesoramiento, análisis de la práctica educativa y tic en educación. Universidad de Extremadura. Cabo Verde, 2017. Acesso aos 10 de Janeiro de 2019. Disponivel em https://pdfs.semanticscholar.org/3f25/2367010c559d9836d3ab396efd9b68775145.pdf? ga=2 $.91247001 .2070658363 .1565768323-1918248042.1565768323$

VIVEIROS, J. M. T. N. O insucesso a matemática na transição para o $10^{\circ}$ ano: um estudo centrado nos percursos de ensino e de aprendizagem em contexto escolar. Tese apresentada à Faculdade de Psicologia e de Ciências da Educação da Universidade do Porto, para obtenção do grau de Doutor em Ciências da Educação. Universidade do Porto. Portugal, 2012. Acesso aos 13 de fevereiro de 2019. Disponivel em https://repositorioaberto.up.pt/bitstream/10216/83249/2/124721.pdf

Recebido: 14/08/2019

Aprovado: 21/09/2019 